\title{
Structural and Functional Changes Induced in the Nicotinic Acetylcholine Receptor by Membrane Phospholipids
}

\author{
Asia M. Fernández-Carvajal, ${ }^{* 1}{ }^{1}$ José A. Encinar, ${ }^{1}$ José Antonio Poveda, ${ }^{1}$ \\ Entilio de Juan, ${ }^{2}$ Juan Martínez-Pinna, ${ }^{2}$ Isabel Ivorra, ${ }^{2}$ José Antonio Ferragut, ${ }^{1}$ \\ Andrés Morales, ${ }^{2}$ and José Manuel González-Ros ${ }^{1}$
}

'Instituto de Biología Molecular y Celular, Universidad Miguel Hernández, Elche, Spain; and ${ }^{2}$ División Fisiología, Universidad de Alicante, Alicante, Spain

\section{Introduction}

Ligand-gated ion channels (LGICs) constitute an important family of complex membrane proteins acting as receptors for neurotransmitters (Barnard, 1992; Ortells and Lunt, 1995). The nicotinic acetylcholine receptor (nAChR) from Torpedo is the most extensively studied member of the LGIC family and consists of a pentameric transmembrane glycoprotein composed of four different polypeptide subunits $(\alpha, \beta, \gamma$, and $\delta)$ in a 2:1:1:1 stoichiometry (Galzi and Changeux, 1995; Hucho et al., 1996) that are arranged pseudosymmetrically around a central cationselectiveion channel. Conformational transitions, from the closed (nonconducting), to agonist-induced open (ion-conducting), to desensitized (nonconducting) states, are critical for functioning of the nAChR (Karlin, 2002). The ability of the $\mathrm{nAChR}$ to undergo these transitions is profoundly influenced by the lipid composition of the bilayer (Barrantes, 2004).

Despite existing information on lipid dependence of AChR function, no satisfactory explanation has been given on the molecular events by which specific lipids exert such effects on the activity of an integral membrane protein. To date, several hypotheses have been entertained, including (1) indirect effects of lipids through the alteration of properties of the bilayer, such as fluidity (an optimal fluidity hypothesis [Fong and McNamee, 1986]) or membrane curvature and lateral pressure (Cantor, 1997; de Kruijff, 1997), or (2) direct effects through binding of lipids to defined sites on the transmembrane portion of the protein (Jones and McNamee, 1988; Blanton and Wang, 1990; Fernández et al., 1993; Fernández-Ballester et al., 1994), which has led to the postulation of a possible role of certain lipids as peculiar allosteric ligands of the protein.

In this paper wehave reconstituted purified AChRs from Torpedo into complex multicomponent lipid vesicles in which the phospholipid composition has been systematically altered. Stopped-flow rapid kinetics of cation translocation and Fourier transform-infrared (FT-IR) spectroscopy studies have been used to illustrate the lipid dependence of both AChR function and AChR secondary structure, respectively.

\section{Results and Discussion}

Purified AChR from Torpedo marmorata has been reconstituted at high (3500:1) phospholipid to protein molar ratio into vesicles containing egg phosphatidylcholine (PC), cholesterol, and different phospholipids (egg PA, egg PG, and egg PE) as probes to explore the effects of phospholipids on protein function and structure by fluorescence and IR spectroscopy.

Agonist-mediated cation translocation through reconstituted AChR was monitored by using a stopped-flow/fluorescence-quenching assay of $\mathrm{Tl}^{+}$ influx (González-Ros etal.,1984). When AChR is reconstituted in vesicles of $\mathrm{PC} /$ cholesterol mixtures or those containing PE, it completely lacks the ability to activate the characteristic cation channel in response

*Author to whom all correspondence and reprint requests should be addressed. E-mail: asia.fernandez@umh.es 


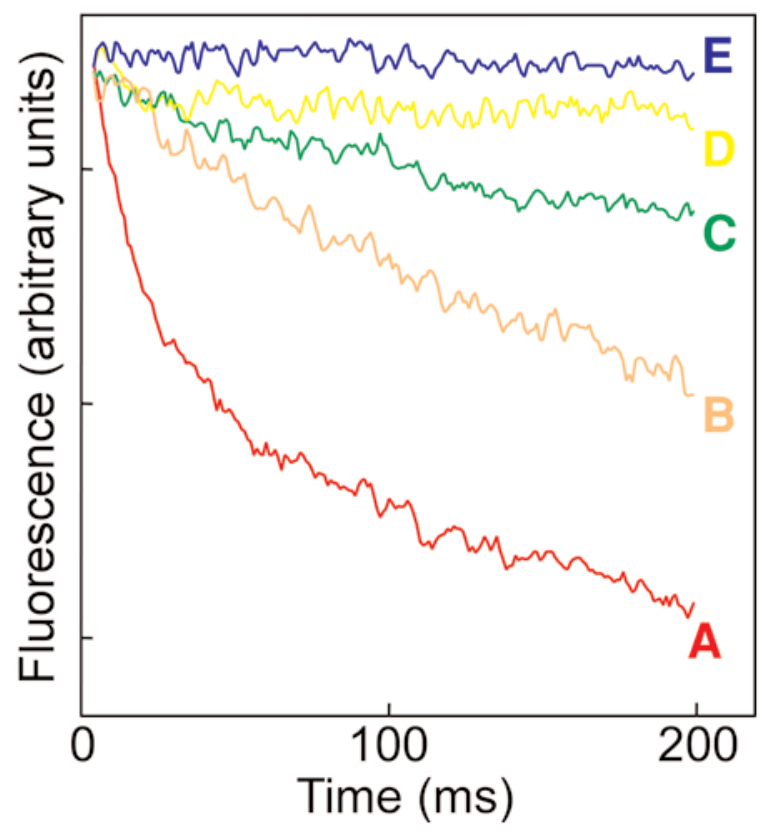

Fig. 1. Stopped-flow recordings of the rapid collisional quenching of 1,3,6,8-pyrenetetrasulfonic acid (PTSA) fluorescence entrapped in reconstituted AChR vesicles by externally added $\mathrm{Tl}^{+}$. The reconstituted vesicles in $10 \mathrm{mM}$ HEPES buffer ( $\mathrm{pH} 7.4), 200 \mathrm{mMNaNO}$, were rapidly mixed with an equal volume of $10 \mathrm{mM}$ HEPES buffer $(\mathrm{pH} 7.4)$, $170 \mathrm{mMNaNO}, 30 \mathrm{mMTINO}$, containing increasing concentrations of carbamylcholine ranging from 0 to $500 \mu \mathrm{M}$ (final concentration), using a SLM 8000 fluorimeter equipped with a stopped-flow accessory. Shown is a comparison of $\mathrm{Tl}^{+}$influx response to $500 \mu \mathrm{M}$ carbamylcholine in reconstituted $A C h R$ membranes prepared from whole asolectin lipids (A) or from lipid mixtures containing 25 mol\% of cholesterol, $50 \mathrm{~mol} \%$ of egg PC, and $25 \mathrm{~mol} \%$ of either PA (B), PG (C), PE (D), or PC (E).

to the presence of cholinergic agonists, so these samples are considered nonfunctional. In contrast, the presence of $25 \mathrm{~mol} \%$ of PA or PG in reconstituted vesicles partly restores AChR activity, reaching - in the case of PA-about one-half of the maximal response seen in the samples reconstituted in whole asolectine lipids and used as a reference for full functional reconstitution. These samples are considered functional (Fig. 1).

These lipid modulations of $\mathrm{nAChR}$ function observed in in vitro systems (stopped-flow rapidkinetics studies) have been corroborated in vivo using the Xenopus oocyte model. In these experiments purified $\mathrm{nAChRs}$ reconstituted in different lipid matrix are injected into oocytes, where they are efficiently inserted in the plasma membrane. Using the voltage clamp technique we observed that the $\mathrm{nAChR}$ in $\mathrm{PC} /$ cholesterol reversibly recovered

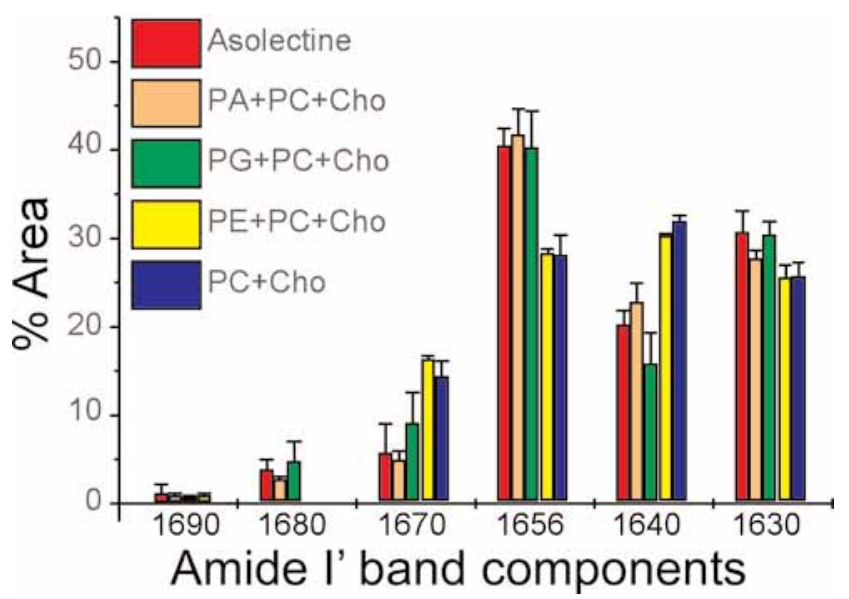

Fig. 2. The diagram shows the statistics of our band-fitting analysis in all the reconstituted samples processed. The main difference between functional (asolectin, $\mathrm{PA}+\mathrm{PC}+\mathrm{Cho}$ [cholesterol], $\mathrm{PG}+\mathrm{PC}+\mathrm{Cho}$ ) and nonfunctional ( $\mathrm{PE}+\mathrm{PC}+\mathrm{Cho}$, $\mathrm{PC}+\mathrm{Cho}$ ) reconstituted samples is that the latter exhibit a much higher proportion of nonordered $\left(1640 \mathrm{~cm}^{-1}\right)$ structure at the expense of a decreased proportion of $\alpha$-helical structure $\left(1656 \mathrm{~cm}^{-1}\right)$. In contrast, the $\beta$-structure component at $1630 \mathrm{~cm}^{-1}$ seems fairly unaffected by reconstitution in the different lipid media. Also, other changes in minor spectral components, such as the practical disappearance of the band at $1680 \mathrm{~cm}^{-1}$ and the increase in the $1670 \mathrm{~cm}^{-1}$ band in the nonfunctional samples, can be observed.

its function and the ACh current was higher when the protein was previously reconstituted in PA. These results suggest that the system is sufficiently dynamic to allow the injected lipid around $n A C h R$ to be exchanged for lipids from its own oocyte membrane, but they also suggest that PA must establish a tighter interaction resulting in an increase in protein activity.

To detect possible structural changes associated with lipid nAChR modulation, different spectroscopic studies have been done, mainly through analysis of the FT-IR amide I' band. It is observed that the conformation-sensitive, IR amide I' band in the spectrum of the protein reconstituted in the PA-containing matrix resembles closely that seen in fully functional samples reconstituted in whole asolectin lipids. On the other hand, such spectra differ the most from those obtained from inactive samples reconstituted in egg PC/cholesterol mixtures. Lipid membranes in which the $\mathrm{nAChR}$ is fully functional, typically those containing PA and cholesterol, present a higher $\alpha$-helical content relative to nonordered structure. Conversely, $\mathrm{nAcChR}$ reconstituted in lipid membranes in which it is less active, such as those with only zwitterionic phospholipids, the AChR shows a larger proportion 
of nonordered structure. Meanwhile, $\beta$-sheet content remains basically unchanged in all cases (Fig. 2).

Previous studies from our laboratory have demonstrated an increase in nonordered protein structures under conditions that produce a reversible loss of acChR ion channel activity, such as desensitatization by cholinergic agonist (Castresana et al., 1992) or reconstitution in the absence of neutral lipids (Fernández-Ballester et al.,1994). These observations suggest that a certain disorganization of native protein structures might be a common element in all processes leading to reversible loss of AcChR function. These results also indicate that the preservation of AChR function by specific lipids is accompanied by maintaining specific features in the AChR structure.

\section{Acknowledgments}

This work was supported by grant DGI BFI200203410 from the Dirección General de Investigación (Spain).

\section{References}

Barnard E.A. (1992) Receptor classes and the transmittergated ion channels. Trends Biochem. Sci. 17, 368-374.

Barrantes F. J. (2004) Structural basis for lipid modulation of nicotinic acetylcholine receptor function. Brain Res. 47, 71-95.

Blanton M. P. and Wang H. H. (1990) Photoaffinity labeling of the Torpedo californica nicotinic acetylcholine receptor with an aryl azide derivative of phosphatidylserine. Biochemistry 29, 1186-1194.

Cantor R. S. (1997) Lateral pressures in cell membranes: a mechanism for modulation of protein function. J. Phys. Chem. 101, 1323-1325.
Castresana J., Fernández -Ballester G., Fernández A. M., Laynez J. L., Arrondo J. L., Ferragut J. A., and González J. M. (1992) Protein structural effects of agonist binding to the nicotinic acetylcholine receptor. FEBS Lett. 314, 171-175.

de Kruijff B. (1997) Biomembranes. Lipids beyond the bilayer. Nature 386, 129,130.

Fernández A. M., Fernández-Ballester G., Ferragut J. A., and González-Ros J. M. (1993) Labeling of the nicotinic acetylcholine receptor by a photoactivatable steroid probe: effects of cholesterol and cholinergic ligands. Biochim. Biophys. Acta 1149, 135-144.

Fernández-Ballester G., Castresana J., Fernández A. M., Arrondo J. L., Ferragut J. A., and González-Ros J. M. (1994) Role of cholesterol as a structural and functional effector of the nicotinic acetylcholine receptor. Biochem. Soc. Trans. 22, 776-780.

Fong T. M. and McNamee M.G. (1986) Correlation between acetylcholine receptor function and structural properties of membranes. Biochemistry 25, 830-840.

Galzi J. L. and Changeux J. P. (1995) Neuronal nicotinic receptors: molecular organization and regulations. Neuropharmacology 24, 563-582.

González-Ros J. M., Ferragut J. A., and Martinez-Carrion M. (1984) Binding of anti-acetylcholine receptor antibodies inhibits the acetylcholine receptor mediated cation flux. Biochem. Biophys. Res. Commun. 120, 368-375.

Hucho F., Tsetlin V. I., and Machold J. (1996) The emerging three-dimensional structure of a receptor. The nicotinic acetylcholine receptor. Eur. J. Biochem. 239, 539-557.

Jones O. T. and McNamee M. G. (1988) Annular and nonannular binding sites for cholesterol associated with the nicotinic acetylcholine receptor. Biochemistry 27, 2364-2374.

Karlin A. (2002) Emerging structure of the nicotinic acetylcholine receptors. Nat. Rev. Neurosci. 3, 102-114.

Ortells M. O. and Lunt G. G. (1995) Evolutionary history of the ligand-gated ion-channel superfamily of receptors. Trends. Neurosci. 18, 121-127. 